\title{
Platelet Function Test in Coronary Artery Bypass Grafting: Does It Predict Postoperative Bleeding?
}

\author{
Sandeep Sharan ${ }^{1}$ Poonam Malhotra Kapoor ${ }^{2}$ Minati Choudhury ${ }^{2}$ Mohit Prakash ${ }^{1}$ \\ Ujjwal K. Chowdhury ${ }^{3}$ Milind Hote ${ }^{3}$ Vajala Ravi ${ }^{4}$
}

${ }^{1}$ Department of Cardiac Anaesthesia, All India Institute of Medical

Address for correspondence Poonam Malhotra Kapoor, MD, DN|B, Sciences, New Delhi, India

${ }^{2}$ Department of Cardiac Anaesthesiology, All India Institute of Medical Sciences, New Delhi, India

${ }^{3}$ Department of Cardio Thoracic Vascular Surgery (CTVS), All India Cardiac Anaesthesiology, All India Institute of Medical Sciences, New Delhi 110029, India (e-mail: drpoonamaiims@gmail.com).

Institute of Medical Sciences, New Delhi, India

${ }^{4}$ Department of Statistics, Delhi University, Lady Sriram College,

New Delhi, India

J Card Crit Care 2021;5:186-195.

\section{Abstract \\ Keywords \\ - coronary artery bypass grafting \\ - platelet function aggregometry \\ - point of care testing \\ - ROTEM}

Background Patients undergoing on-pump coronary artery bypass grafting (CABG) are at increased risk of perioperative bleeding and morbidity associated with transfusion as a result of acquired and pharmacologically induced impaired platelet function. Settings and Design In this a prospective observational study where 52 patients underwent on-pump CABG were analyzed with ROTEM platelet aggregometry.

Materials and Methods Patients were assigned to the "nonexcessive" and "excessive" postoperative bleeding groups according to the postoperative chest tube drainage over 24 hours. Platelet function was assessed by ROTEM platelet using three different activators (arachidonic acid, adenosine diphosphate, and thrombin receptoractivating peptide), at two perioperative time points (T1, before heparinization and $\mathrm{T} 2$, 5-10 minutes after protamine administration).

Results There were no differences regarding demographic, pre-cardiopulmonary bypass (CPB) platelet count and antiplatelet therapy. Platelet function was impaired over the time course in all parameters with three different activators. At T2 point, area under the curve (AUC) of all the three platelet indices, that is, TRAPTEM, ARATEM, and ADPTEM, showed significant difference between excessive and nonexcessive groups. At both $\mathrm{T} 1$ and $\mathrm{T} 2$ points, the amplitude after 6 minutes (A6) and maximum slope (MS) parameters of TRAPTEM, ARATEM, and ADPTEM tests were not significantly different in excessive and nonexcessive groups. At T1 point, AUC was also not significantly different in all three ROTEM platelet tests. Results after protamine administration showed correlation with postoperative chest tube drainage. Cut-off values, as determined by receiver operating characteristics (ROC) analyses, had a consistently weak positive
DOI https://doi.org/ $10.1055 / \mathrm{s}-0042-1742402$. ISSN 2457-0206. (c) 2022. Official Publication of The Simulation Society (TSS), accredited by International Society of Cardiovascular Ultrasound (ISCU). All rights reserved.

This is an open access article published by Thieme under the terms of the Creative Commons Attribution-NonDerivative-NonCommercial-License, permitting copying and reproduction so long as the original work is given appropriate credit. Contents may not be used for commercial purposes, or adapted, remixed, transformed or built upon. (https://creativecommons.org/ licenses/by-nc-nd/4.0/)

Thieme Medical and Scientific Publishers Pvt. Ltd., A-12, 2nd Floor, Sector 2, Noida-201301 UP, India 
predictive value for all tests at $\mathrm{T} 2$ time point, whereas negative predictive values were higher.

Conclusion Platelet function analysis using ROTEM platelet can help to exclude platelet dysfunction as the reason for bleeding after cardiac surgery. Point-of-care platelet function analysis, particularly in combination with viscoelastic testing can reduce perioperative bleeding and transfusion requirements, as well as improve patient outcomes in cardiac surgery.

\section{Introduction}

Cardiac surgery using cardiopulmonary bypass (CPB) creates a risk of perioperative excessive bleeding; transfusion of red blood cells; transfusion of procoagulant blood products like fresh frozen plasma (FFP), platelet concentrate, and cryoprecipitate; and complications associated with transfusion. ${ }^{1}$

From clinical studies, we have strong evidence that blood and blood products' transfusions during cardiac surgery have increased risk of serious postoperative morbidities including infections, atrial fibrillation, respiratory complications, acute kidney injury, duration of intensive care unit (ICU) and hospital stay, treatment costs, and short-term and longterm mortality. ${ }^{2,3}$

Excessive bleeding during and after cardiac surgery has an incidence of approximately 20\%. ${ }^{4}$ Excessive bleeding and subsequent requirement for blood product administration and mediastinal reexploration is associated with significant morbidity and mortality. ${ }^{5}$ Reoperation for bleeding is required in 2.3 to $8 \%$ patients undergoing coronary artery bypass graft (CABG) surgery. ${ }^{6-8}$

Coagulopathy associated with cardiac surgery is multifactorial. Platelet dysfunction, excessive fibrinolysis, hypothermia, preoperative anemia, and deficiency of coagulation factors or their dilution are all suggested etiologies of postoperative bleeding. ${ }^{4}$

Among these, the most important is thought to be platelet dysfunction which occurs as a result of the interplay of acquired and pharmacologically induced factors. ${ }^{9,10}$ Patients suffering from coronary artery disease are usually advised to stop antiplatelet medication a few days prior to CABG surgery to reduce the incidence of postoperative bleeding. ${ }^{11}$ Current revascularization guidelines therefore recommend that clopidogrel and ticagrelor are discontinued 5 days before surgery and prasugrel 7 days before elective surgery, but the patient's condition may render this impossible. ${ }^{12,13}$ Patients who are still on antiplatelet drugs are at an increased risk of postoperative bleeding. ${ }^{14,15}$ Transfusions of blood and blood products have got deleterious effects, and hence efforts should be made to minimize transfusion. ${ }^{16}$ Currently, the transfusion of blood and blood components to manage postoperative bleeding after CABG remains largely empirical, with considerable variation among institutions. ${ }^{17}$ Algorithm-based coagulation therapy has been shown to be superior to empiric therapy based on clinical judgment. ${ }^{8-10}$ Hence, there is a need to have objective tests to demonstrate platelet dysfunction before platelet transfusion. ${ }^{17,18}$ Several devices' platelet function tests have been reported in clinical studies to evaluate platelet dysfunction and quantify the need for antiplatelet therapy. ${ }^{14,17}$ Those devices range from highly sophisticated ones, such as light transmittance aggregometers and whole blood flow cytometers, to simple point-of-care technologies. The problem is that no consensus exists concerning several issues such as which device is optimal, what cut-off values to apply for discrimination of bleeding risk, and how to proceed with antiplatelet strategies once the results of platelet testing are determined. ${ }^{19}$

We hypothesized that objective measurement of platelet function can be useful in prediction of postoperative blood loss and in guiding postoperative transfusion requirements (blood and platelets) and the need for surgical reexploration. Hence, we designed a prospective observational study to investigate the association between platelet function by ROTEM platelet aggregometry and postoperative blood loss.

\section{Materials and Methods}

This prospective observational study was performed in the Department of Cardiac Anaesthesiology, All India Institute of Medical Sciences (AIIMS), New Delhi, after approval of the Institutional Ethical committee.

Approval of Institutional Ethical Committee was obtained vide letter number IECPG-583/24.10.2019, RT-12/28.11.2019 dated November 11, 2019. A written informed consent was obtained from all the patients before the screening in the study.

It is a prospective observational study and 52 patients who underwent on-pump CABG were analyzed with ROTEM platelet aggregometry in this investigation.

\section{Methods of Collection of Data}

\section{Selection of Cases}

\section{Inclusion Criteria}

Patients of either gender, belonging to American Society of Anesthesiologists (ASA) grades I to III undergoing isolated CABG using CPB.

\section{Exclusion Criteria}

- Patients undergoing off-pump CABG.

- Patients with known coagulopathy.

- Patients undergoing emergency surgery. 
- Patients with preoperative renal or hepatic impairment.

- Platelet (PLT) count $<100 \times 10^{9} / \mathrm{L}$.

\section{Recruitment Process}

After explanation of the study protocol, written and informed consent was obtained before the operation from all the participants found to be eligible.

\section{Methodology}

Preanesthetic examinations were performed 1 day prior to surgery. The procedure was explained to the patient and written informed consent were obtained. All patients received premedication in the form of injection morphine $0.1 \mathrm{mg} / \mathrm{kg}$ and injection promethazine $0.5 \mathrm{mg} / \mathrm{kg}$. Anesthesia was induced with etomidate $(0.2-0.3 \mathrm{mg} / \mathrm{kg})$ or thiopentone (3-5 mg/kg), fentanyl $(2-3 \mu \mathrm{g} / \mathrm{kg})$ and rocuronium bromide $(0.8-1 \mathrm{mg} / \mathrm{kg})$. Patient was intubated with portex endotracheal tube of appropriate size. Anesthesia was maintained using sevoflurane $(0.5-1 \%)$ or isoflurane $(0.4-0.8 \%)$ in oxygen air mixture with intermittent doses of fentanyl, midazolam, and cisatracurium or vecuronium which is the standard practice in our institute. All patients were monitored with five-lead electrocardiography, $\mathrm{SPO}_{2}$, invasive blood pressure, central venous pressure, temperature, capnography, and urine output.

Patients were operated according to standard protocol with CPB. Before cannulation, heparin ( $400 \mathrm{IU} / \mathrm{kg}$ ) was given and supplemented as required to maintain an Activated Clotting Time $(\mathrm{ACT})>480$ seconds. The standard uncoated $\mathrm{CPB}$ circuit was primed with 1-L lactated ringer solution, sodium bicarbonate of $50 \mathrm{~mL}, 0.5 \mathrm{gm} / \mathrm{kg}$ mannitol, and 10,000 IU heparin. The ascending aorta and atriocaval cannulation were done for CPB. CPB was performed with membrane oxygenator (CAPIOX FX25 with hard-shell reservoir) using standard nonpulsatile technique. After decannulation, heparin was neutralized with protamine sulfate (1-mg protamine per $100-$ IU heparin). If ACT was more than 170 seconds or baseline after heparin reversal, a supplementary dose of 50-mg protamine was given.

Patients were given packed red blood cell (PRBC), and blood components after following an AIIMS algorithm-based transfusion of blood components (-Fig. 1). This algorithm will aid us to improve outcomes immensely, especially in postoperative bleeding control. It is a ROTEM-based platelet function tests using three different indicator agents, approved by our Ethics Committee. ${ }^{20}$

PRBCs were added to the reservoir to maintain a hematocrit greater than $30 \%$. ACT and blood gas analysis were done half hourly. Pump flow was maintained between 2.2 and 3 $\mathrm{L} / \mathrm{m}^{2}$ body surface area. The target mean arterial pressure during СРВ was $60 \mathrm{~mm} \mathrm{Hg}$. If necessary, epinephrine was given to reach this value. Distal coronary anatomizes were performed on an arrested heart during a single period of aortic cross-clamping. Weaning from CPB was initiated once the patient's rhythm had stabilized and normothermia had been achieved. Isotropic support was initiated to maintain a cardiac index $2.2 \mathrm{~L} / \mathrm{min} / \mathrm{m}^{2}$. The preferred isotropic agent was dobutamine. Nor epinephrine was used if dobutamine produced excessive vasodilatation. Epinephrine or dopamine was used if the hemodynamic performance remained inadequate. Postoperative bleeding was defined as the total amount of chest tube drainage during the first 24 hours. After surgery, the decision to transfuse PRBCs was based on clinical and hemodynamic status with aim of hemoglobin $10 \mathrm{gm} / \mathrm{dL}$. FFP was transfused for ongoing significant bleeding and increased INR. Platelet was transfused if platelet count was $<100 \times 10^{6} /$ $\mathrm{dL}$ and significant bleeding. Blood samples for ROTEM platelet aggregometry were obtained at two different time points: after induction of anesthesia before heparinization (T1), and 5 to 10 minutes after protamine administration (T2) in a tubecontaining citrate and analyzed within 1 hour, after decalcification with $20-\mu \mathrm{L} \mathrm{CaCl}_{2}$. All measurements were performed by physicians trained to operate study device and not directly involved in the patient's care.

Anesthesiologists and surgeons were blinded to the results of the ROTEM platelet measurements. Results of ROTEM platelet were not available to the operating room staff or the ICU team. Surgical reexploration of the mediastinum for excessive bleeding was noted, along with any surgical explanation of bleeding. An AIIMS algorithm-based approach was applied to transfuse according to the platelet reagent activates of ADPTEM, ARATEM, or TRAPTEM as depicted in -Fig. 1.

\section{Parameters Evaluated}

Demographic and preoperative data, like sex, age, height, body weight, duration of $\mathrm{CPB}$, postoperative chest drain output, use of blood, and blood products, were noted in all patients. A baseline heart rate, blood pressure, saturation, central venous pressure, and routine hematological investigations were noted. Patients were assigned to the "nonexcessive" and "excessive" postoperative bleeding groups, respectively, according to the postoperative chest tube drainage over 24 hours postoperatively divided by their respective body weight ( 24 hours of chest tube drainage in $\mathrm{mL} / \mathrm{kg}$ ). If drainage over 24 hours exceeds the 75 th percentile of the whole study population, patients were characterized as "excessively bleeding." A similar definition has already been described in the literature. ${ }^{21,22}$

For each test, different parameters, after the recognition and computation by the integrated software detection: the area under the aggregation curve (AUC), the amplitude after 6 minutes (A6) and the maximum slope (MS) were noted at $\mathrm{T} 1$ and T2 time points. Anesthetists and surgeons (clinicians managing the patient in ICU) were blinded to the results of the ROTEM platelet aggregometry measurements.

\section{Statistical Methods}

The quantitative variables are expressed as means and compared between groups using unpaired $t$-test. Qualitative variables are compared between groups using Chi-square test. Receiver operating characteristic (ROC) curves are made for identifying threshold values of parameters for predicting excessive bleeding, and sensitivity, specificity, positive predictive value (PPV), negative predictive value (NPV), and 


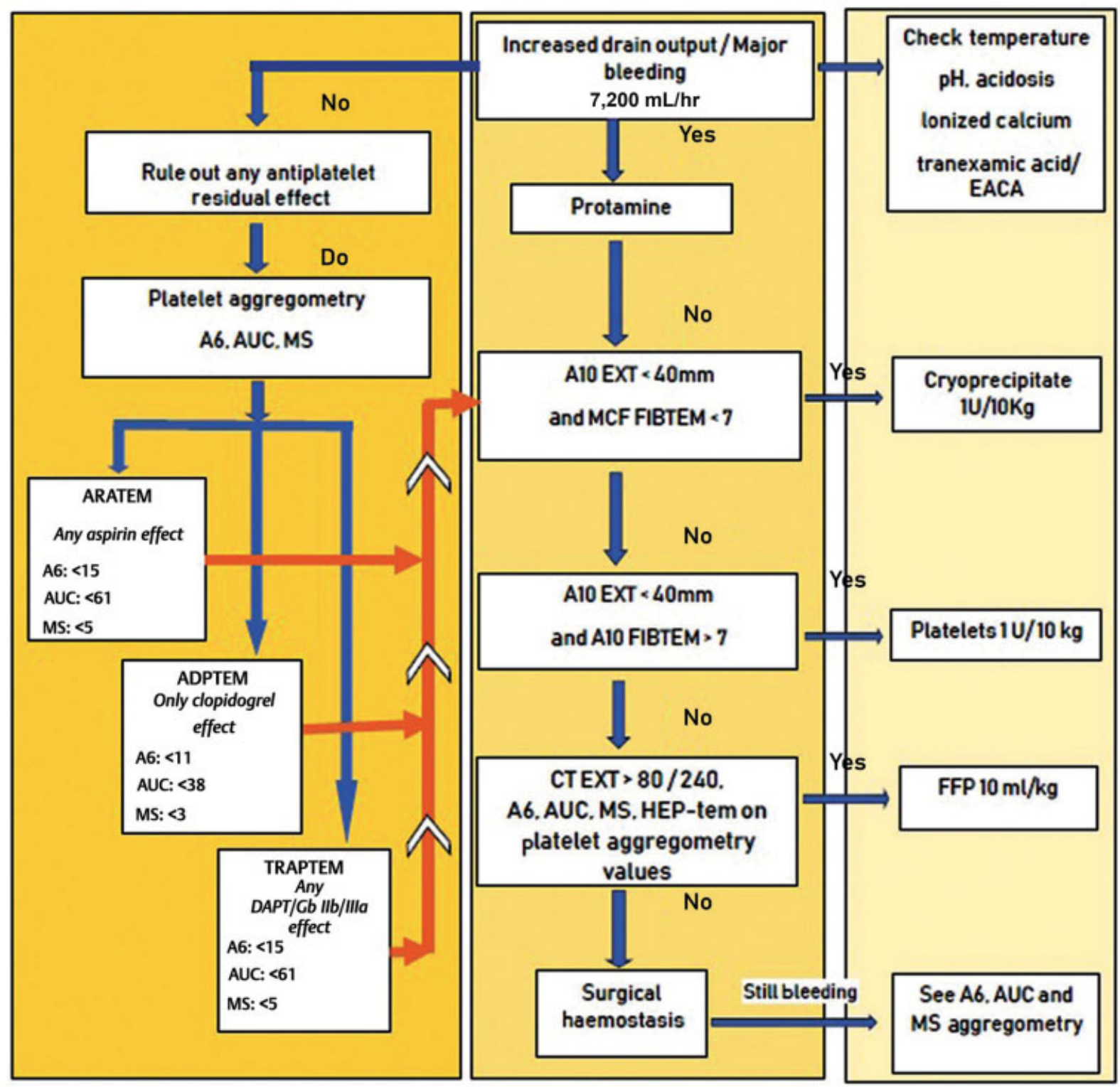

Fig. 1 Algorithm used at the All India Institute of Medical Sciences (AIIMS) for testing platelet aggregometry in coronary artery bypass grafting patients. A6, amplitude after 6 minutes; AUC, area under the curve; FFP, fresh frozen plasma; MS, maximum slope.

diagnostic accuracy are calculated. A $p$-value of $<0.05$ is considered statistically significant. The data are stored in MS Excel spreadsheet and statistical analysis was performed using IBM Statistical Package for Social Sciences (SPSS) version 20.0 .

\section{Results}

A total of 75 patients were assessed for eligibility. Four patients did not give consent for participation. Six patients were on low molecular weight heparin due to significant left main disease and they were not included due to not meeting inclusion criteria. Four patients had chest reexploration and due to an obvious surgical cause of bleeding, they were excluded for analysis. Six patients were excluded from data analysis due to a lack of reagents. Three patients had sudden hemodynamic instability postoperatively followed by intra- aortic balloon pump insertion prior, and they were excluded from study. The final sample size was 52 .

\section{Group Allocation}

As stated in our hypothesis, we created two groups: excessive bleeding and nonexcessive bleeding groups. We were hypothesized that "if drainage over 24 hours exceeds the 75 th percentile of the whole study population, patients will be characterized as excessively bleeding." After data collection, we found that there was no obvious drain output difference from 21 st to 36 th percentiles. We allocated 11 patients to excessively bleeding (excessive) group. The rest 41 patients were assigned to nonexcessive group (-Table $\mathbf{1}$ ).

\section{Drain Output in Two Groups}

In excessive bleeding group, the mean chest drain output in first 6 hours and total in 24 hours was $450.91 \pm 87.57 \mathrm{~mL}$ and 
Table 1 Group allocation into two groups

\begin{tabular}{|l|l|l|}
\hline Bleeding & $\boldsymbol{n}$ & $\%$ \\
\hline Excessive & 11 & 21.15 \\
\hline Nonexcessive & 41 & 78.85 \\
\hline Total & 52 & 100 \\
\hline
\end{tabular}

Table 2 Chest drain output

\begin{tabular}{|l|l|l|l|l|l|}
\hline \multirow{2}{*}{$\begin{array}{l}\text { Drain } \\
\text { output }\end{array}$} & \multicolumn{2}{|l|}{ Excessive } & \multicolumn{2}{l|}{ Nonexcessive } & \multirow{2}{*}{$p$-Value } \\
\cline { 2 - 5 } & Mean & \pm SD & Mean & \pm SD & \\
\hline $\begin{array}{l}\text { In first } \\
\text { 6 hours }\end{array}$ & 450.91 & \pm 87.57 & 182.93 & \pm 24.32 & $<0.001$ \\
\hline $\begin{array}{l}\text { In } \\
24 \text { hours }\end{array}$ & 798.18 & \pm 168.04 & 330.24 & \pm 41.2 & $<0.001$ \\
\hline
\end{tabular}

Abbreviation: SD, standard deviation.

$798.18 \pm 168.04 \mathrm{~mL}$, respectively. In nonexcessive group, it was $798.18 \pm 168.04 \mathrm{~mL}$ and $330.24 \pm 41.2 \mathrm{~mL}$, respectively (-Table 2).

\section{Basic Demographic Variables}

The patient demographic variables are summarized in - Table 2. The mean age of patients who had excessive bleeding was $57.00 \pm 19.78$ years while patients in nonexcessive group was $61.59 \pm 8.94$ years. Thus, age in both the groups was comparable and was not statistically different $(p=0.072)$. The mean weight $(\mathrm{kg})$ and height $(\mathrm{cm})$ of the excessive group was $68.91 \pm 9.13$ and $169.55 \pm 4.03$, respectively. In nonexcessive group, they were $68.46 \pm 11.07$ and $167.85 \pm 6.06$, respectively. Difference was statically insignificant ( $p=0.451$ and 0.193 , respectively). Difference in mean BMI in both the groups was also statistically insignificant ( $p=0.408$; - Table 3 ).

Majority of the patients in the study population were male (90.91\% in excessive group and $82.93 \%$ in nonexcessive group) and had New York Heart Association (NYHA) 2 or 3 symptoms (81.82 in excessive group and $82.93 \%$ in nonexcessive group; - Table 4).

\section{Antiplatelet Therapy}

There were no differences in prevalence of excessive bleeding that observed among patient groups based on aspirin only and dual antiplatelet therapy ( $p=0.219$; - Table 5).
Table 4 Antiplatelet therapy discontinuation

\begin{tabular}{|l|l|l|l|l|l|}
\hline \multirow{2}{*}{$\begin{array}{l}\text { Antiplatelet } \\
\text { iscontinuation }\end{array}$} & \multicolumn{4}{|l|}{ Excessive } & \multicolumn{2}{l|}{$\begin{array}{l}\text { Nonexces- } \\
\text { sive }\end{array}$} & \multirow{2}{*}{-Value } \\
\cline { 2 - 5 } & $n$ & $\%$ & $n$ & $\%$ & \\
\hline 1 & 1 & 9.09 & 1 & 2.44 & 0.154 \\
\hline 2 & 0 & 0.00 & 1 & 2.44 & 0.300 \\
\hline 3 & 2 & 18.18 & 3 & 7.32 & 0.139 \\
\hline 4 & 2 & 18.18 & 4 & 9.76 & 0.219 \\
\hline 5 & 6 & 54.55 & 32 & 78.05 & 0.059 \\
\hline Total & 11 & 100 & 41 & 100 & \\
\hline
\end{tabular}

Table 5 Antiplatelet therapy

\begin{tabular}{|l|l|l|l|l|l|}
\hline \multirow{2}{*}{ Anti-platelet } & \multicolumn{4}{|l|}{ Excessive } & \multicolumn{2}{l|}{$\begin{array}{l}\text { Nonexces- } \\
\text { sive }\end{array}$} & \multirow{2}{*}{$p$-Value } \\
\cline { 2 - 6 } & $\boldsymbol{n}$ & $\%$ & $\boldsymbol{n}$ & $\%$ & \\
\hline Aspirin & 2 & 18.18 & 4 & 9.76 & \multirow{2}{*}{0.219} \\
\hline Aspirin + clopid & 9 & 81.82 & 37 & 90.24 & \\
\hline Total & 11 & 100 & 41 & 100 & \\
\hline
\end{tabular}

No significant difference was found between groups based on day of discontinuation of antiplatelet (-Table 4). In excessive and nonexcessive groups, baseline platelet count and hemoglobin were comparable but there were significant decreases post-CPB.

\section{Cardiopulmonary Bypass Time and Aortic Cross Time} The mean CPB and aortic cross (Ao X) clamp times of the excessive group were $117.00 \pm 39.27 / \mathrm{min}$ and $68.64 \pm 25.23 /$ min, respectively. In nonexcessive group, mean $\mathrm{CPB}$ and $\mathrm{Ao} \mathrm{X}$ clamp times were $76.83 \pm 29.21 / \mathrm{min}$ and $44.83 \pm 16.01 / \mathrm{min}$, respectively. Both CPB and Ao X clamp times were significantly higher in excessive group $(p<0.001)$.

\section{ROTEM Platelet Parameters in the Two Groups}

Comparison of ROTEM platelet measurements between patients with excessive and nonexcessive bleeding and longitudinal assessment over two different points are summarized in - Table 6 .

Longitudinal assessment of platelet function over the two different time points demonstrated significant changes in platelet function assessed by ROTEM platelet in both the groups.

Table 3 Demographic variables: no statistical difference between the two groups

\begin{tabular}{|c|c|c|c|c|c|}
\hline & \multicolumn{2}{|c|}{ Excessive } & \multicolumn{2}{|c|}{ Nonexcessive } & \multirow[t]{2}{*}{$p$-Value } \\
\hline & Mean & $\pm \mathrm{SD}$ & Mean & $\pm \mathrm{SD}$ & \\
\hline Age (y) & 57.00 & \pm 9.78 & 61.59 & \pm 8.94 & 0.072 \\
\hline Weight (kg) & 68.91 & \pm 9.13 & 68.46 & \pm 11.07 & 0.451 \\
\hline Height $(\mathrm{cm})$ & 169.55 & \pm 4.03 & 167.85 & \pm 6.05 & 0.193 \\
\hline BMI $\left(\mathrm{kg} / \mathrm{m}^{2}\right)$ & 23.96 & \pm 3.01 & 24.2 & \pm 3.02 & 0.408 \\
\hline
\end{tabular}

Abbreviations: BMI, body mass index; SD, standard deviation. 
Platelet Function Test in CABG and Its Efficacies Sharan et al. 191

Table 6 Comparison of ROTEM platelet measurements between patients with excessive and nonexcessive bleeding and longitudinal assessment over two different points

\begin{tabular}{|c|c|c|c|c|c|c|c|}
\hline & & & \multicolumn{2}{|c|}{ Excessive } & \multicolumn{2}{|c|}{ Nonexcessive } & \multirow[t]{2}{*}{$p$-Value } \\
\hline & & & Mean & $\pm \mathrm{SD}$ & Mean & $\pm \mathrm{SD}$ & \\
\hline \multirow[t]{9}{*}{ TRAPTEM } & \multirow[t]{3}{*}{ A6 } & T1 & 15.00 & \pm 2.28 & 18.49 & \pm 8.85 & 0.102 \\
\hline & & $\mathrm{T} 2$ & 10.64 & \pm 6.47 & 11.59 & \pm 4.21 & 0.279 \\
\hline & & $p$-Value (T1 vs. T2) & \multicolumn{2}{|l|}{0.033} & \multicolumn{2}{|c|}{$<0.001$} & \\
\hline & \multirow[t]{3}{*}{ MS } & T1 & 5.27 & \pm 2.53 & 5.54 & \pm 2.4 & 0.375 \\
\hline & & $\mathrm{T} 2$ & 3.27 & \pm 2.57 & 3.02 & \pm 1.71 & 0.352 \\
\hline & & p-Value (T1 vs. T2) & \multicolumn{2}{|l|}{0.029} & \multicolumn{2}{|c|}{$<0.001$} & \\
\hline & \multirow[t]{3}{*}{ AUC } & T1 & 64.00 & \pm 12.67 & 71.05 & \pm 24.07 & 0.178 \\
\hline & & $\mathrm{T} 2$ & 35.91 & \pm 19.13 & 51.17 & \pm 15.42 & 0.004 \\
\hline & & $p$-Value (T1 vs. T2) & \multicolumn{2}{|l|}{0.001} & \multicolumn{2}{|c|}{$<0.001$} & \\
\hline \multirow[t]{9}{*}{ ARATEM } & \multirow[t]{3}{*}{ A6 } & T1 & 12.82 & \pm 11.32 & 20.32 & \pm 22.38 & 0.145 \\
\hline & & $\mathrm{T} 2$ & 6.91 & \pm 2.81 & 7.49 & \pm 2.45 & 0.252 \\
\hline & & $p$-Value (T1 vs. T2) & \multicolumn{2}{|l|}{0.083} & \multicolumn{2}{|c|}{$<0.001$} & \\
\hline & \multirow[t]{3}{*}{ MS } & T1 & 3.00 & \pm 0.77 & 3.37 & \pm 1.71 & 0.248 \\
\hline & & $\mathrm{T} 2$ & 2.27 & \pm 1.27 & 2.12 & \pm 0.9 & 0.327 \\
\hline & & p-Value (T1 vs. T2) & \multicolumn{2}{|l|}{0.044} & \multicolumn{2}{|c|}{$<0.001$} & \\
\hline & \multirow[t]{3}{*}{$\mathrm{AUC}$} & T1 & 50.45 & \pm 16.46 & 63.73 & \pm 22.69 & 0.038 \\
\hline & & $\mathrm{T} 2$ & 25.27 & \pm 8.91 & 36.39 & \pm 13.77 & 0.007 \\
\hline & & p-Value (T1 vs. T2) & \multicolumn{2}{|c|}{$<0.001$} & \multicolumn{2}{|c|}{$<0.001$} & \\
\hline \multirow[t]{9}{*}{ ADPTEM } & \multirow[t]{3}{*}{ A6 } & T1 & 15.00 & \pm 3.55 & 13.88 & \pm 4.8 & 0.237 \\
\hline & & $\mathrm{T} 2$ & 10.27 & \pm 3.77 & 11.68 & \pm 2.13 & 0.054 \\
\hline & & $p$-Value (T1 vs. T2) & \multicolumn{2}{|c|}{$<0.001$} & \multicolumn{2}{|l|}{0.002} & \\
\hline & \multirow[t]{3}{*}{ MS } & T1 & 3.82 & \pm 0.98 & 3.39 & \pm 0.67 & 0.047 \\
\hline & & $\mathrm{T} 2$ & 2.91 & \pm 0.94 & 3.83 & \pm 0.92 & 0.003 \\
\hline & & p-Value (T1 vs. T2) & \multicolumn{2}{|l|}{0.008} & \multicolumn{2}{|l|}{0.010} & \\
\hline & \multirow[t]{3}{*}{ AUC } & T1 & 52.18 & \pm 14.29 & 53.12 & \pm 16.91 & 0.433 \\
\hline & & $\mathrm{T} 2$ & 31.09 & \pm 9.48 & 40.15 & \pm 7.9 & 0.001 \\
\hline & & $p$-Value (T1 vs. T2) & 0.001 & & $<0.00$ & & \\
\hline
\end{tabular}

Abbreviations: A6, amplitude after 6 minutes; AUC, area under curve; MS, maximum slope; SD, standard deviation; T1, before heparinization; T2, 5-10 minutes after protamine administration.

At T2 point, AUC of all the three platelet indices, that is, TRAPTEM, ARATEM, and ADPTEM, showed significant difference between excessive and nonexcessive groups. Mean AUCs of the TRAPTEM test at respective T2 point in excessive and nonexcessive groups were $35.91 \pm 19.13$ and $51.17 \pm 15.42$, respectively, and showed a significant difference $(p=0.004)$. For ARATEM, mean AUCs in excessive and nonexcessive groups at respective T2 point were $25.27 \pm 8.91$ and $36.39 \pm 13.77$, respectively, and difference was statically significant $(p=0.007)$. For ADPTEM, mean AUCs in excessive and nonexcessive at respective T2 point were $31.09 \pm 9.48$ and $40.15 \pm 7.9$, respectively, and difference was statically significant $(p=0.001)$.

At both T1 and T2 points, A6 and MS parameters of TRAPTEM, ARATEM, and ADPTEM tests were not significant- ly different in excessive and nonexcessive groups. At T1 point, AUC was also not significantly different in all three ROTEM platelet tests.

The overall test performance for discrimination between patients with or without excessive postoperative bleeding was moderate.

\section{Receiver Operating Characteristic Curve and Its Interpretation: At $\mathbf{5}$ to $\mathbf{1 0}$ Minutes after Protamine Administration for Amplitude after 6 Minutes}

\section{Interpretation}

The area under the ROC curve at T2 for the parameter A6 is given above (-Fig. 2). For TRAPTEM, the area is $50.2 \%$ $(p=0.982)$; for ARATEM, the area is $54.5 \%(p=0.646)$; and 


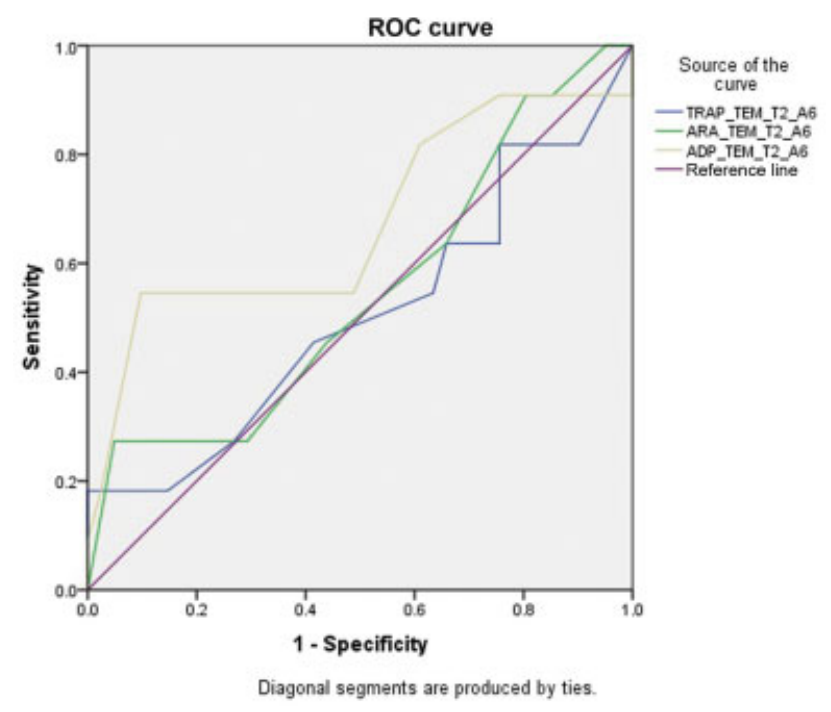

Fig. 2 Receiver operating characteristic (ROC) curve at T2 for A6. A6, amplitude after 6 minutes; T2, 5-10 minutes after protamine administration.

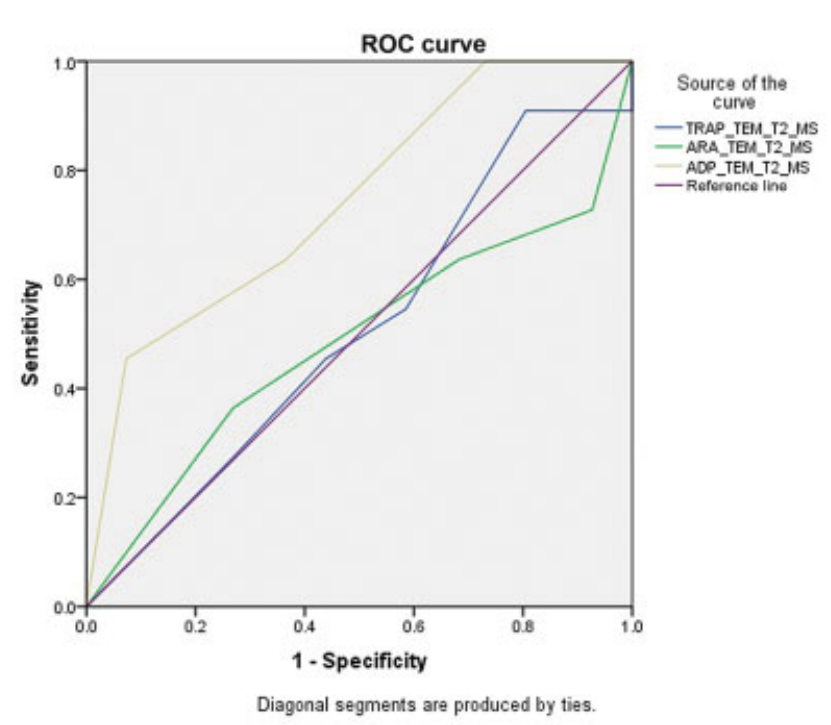

Fig. 3 Receiver operating characteristic (ROC) curve at T2 for MS. MS, maximum slope; T2, 5-10 minutes after protamine administration.

for ADPTEM, the area is $67.4 \%$ ( $p=0.079$ ). None of these are significant and hence may not be good indicators for predicting excessive bleeding (-Fig. $\mathbf{3}$ ).

\section{Receiver Operating Characteristic Curve and Its Interpretation: At $\mathbf{5}$ to $\mathbf{1 0}$ Minutes after Protamine Administration for Maximum Slope}

\section{Interpretation}

The area under the ROC curve at time $\mathrm{T} 2$ for the parameter MS is given above. For TRAPTEM, the area is $50.9 \%$ $(p=0.929)$; for ARATEM, the area is $48.6 \%(p=0.884)$; and for ADPTEM, the area is $74.4 \%(p=0.014)$. Only ADPTEM is found to be significant. For this, a threshold value of $\leq 3.5$ to

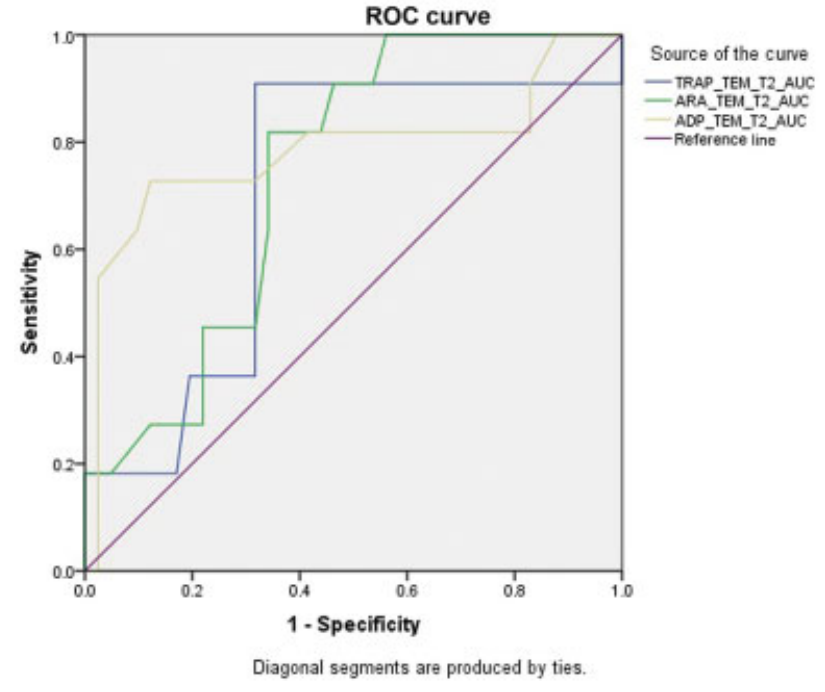

Fig. 4 Receiver operating characteristic (ROC) curve at T2 for AUC. AUC, area under the curve; T2, 5-10 minutes after protamine administration.

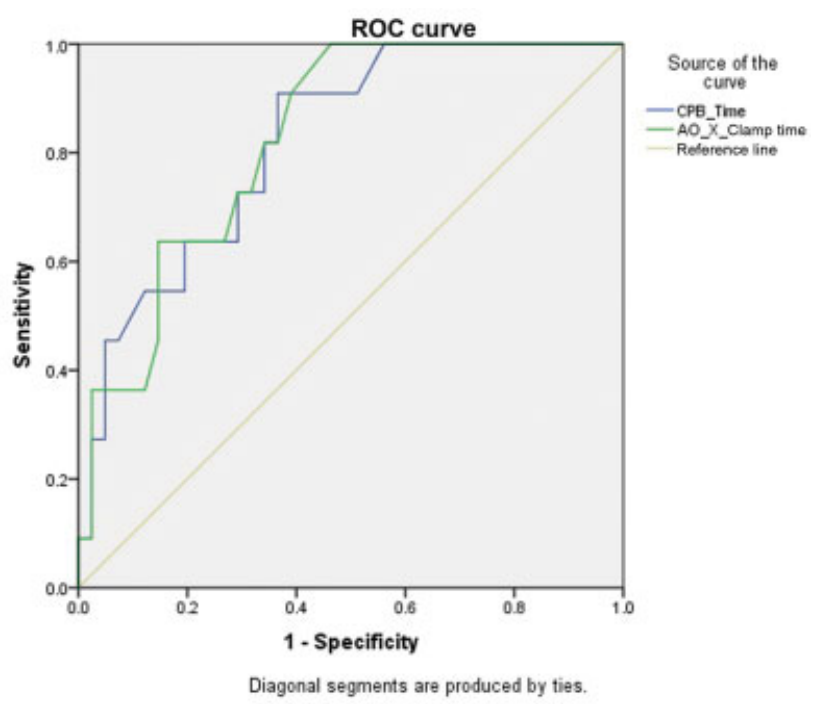

Fig. 5 Receiver operating characteristic (ROC) curve for CPB time and Ao X clamp time. Ao X, aortic cross; CPB, cardiopulmonary bypass.

predict excessive bleeding yields sensitivity of $63.64 \%$, specificity of $63.41 \%$, PPV of $31.32 \%$, NPV of $86.67 \%$, and accuracy of $63.46 \%$ (-Fig. 4 ).

\section{Receiver Operating Characteristic Curve and Its Interpretation: At $\mathbf{2}$ for Area under the Curve}

\section{Interpretation}

The area under the ROC curve at time T2 for the parameter AUC is given above. For TRAPTEM, the area is $70.3 \%$ $(p=0.040)$; for ARATEM, the area is $73.9 \%(p=0.016)$; and for ADPTEM, the area is $78.5 \%(p=0.004)$. For TRAPTEM, a threshold value of $\leq 50$ to predict excessive bleeding yields sensitivity of $90.91 \%$, specificity of $68.29 \%$, PPV of $43.48 \%$, 
NPV of $96.55 \%$, and accuracy of $73.08 \%$. For ARATEM, a threshold value of $\leq 31.5$ to predict excessive bleeding yields sensitivity of $81.82 \%$, specificity of $65.85 \%$, PPV of $39.13 \%$, NPV of $93.10 \%$, and accuracy of $69.23 \%$. For ADPTEM, a threshold value of $\leq 32$ to predict excessive bleeding yields sensitivity of $72.73 \%$, specificity of $87.80 \%$, PPV of $61.54 \%$, NPV of $92.31 \%$, and accuracy of $84.62 \%$ (-Fig. 5).

\section{Receiver Operating Characteristic Curve and Its Interpretation for Cardiopulmonary Bypass and Aortic Cross Clamp Time}

\section{Interpretation}

The area under the ROC curve for CPB time is $82 \%(p=0.001)$ and for AOX clamp time, it is $82.6 \%(p=0.001)$. For CPB time, a threshold value of $\leq 92.5$ to predict excessive bleeding yields sensitivity of $72.73 \%$, specificity of $70.73 \%$, PPV of $40 \%$, NPV of $90.63 \%$, and accuracy of $71.15 \%$. For AO X clamp time, a threshold value of $\leq 49.5$ to predict excessive bleeding yields sensitivity of $72.73 \%$, specificity of $70.73 \%$, PPV of $40 \%$, NPV of $90.63 \%$, and accuracy of $71.15 \%$.

Table 7 Unit of PRBCs transfused

\begin{tabular}{|l|l|l|l|l|l|}
\hline \multirow{2}{*}{$\begin{array}{l}\text { Unit of } \\
\text { PRBC } \\
\text { transfused }\end{array}$} & \multicolumn{2}{|l|}{ Excessive } & \multicolumn{2}{l|}{ Nonexcessive } & \multirow{2}{*}{$p$-Value } \\
\cline { 2 - 5 } & Mean & $\pm S D$ & Mean & $\pm S D$ & \\
\hline On CPB & 0.91 & \pm 0.54 & 1.34 & \pm 0.88 & 0.065 \\
\hline Post-CPB & 3.91 & \pm 0.94 & 1.61 & \pm 0.59 & $<0.001$ \\
\hline
\end{tabular}

Abbreviations: CPB, cardiopulmonary bypass; PRBC, packed red blood cell; SD, standard deviation.

Table 8 Unit of FFP and platelet transfused

\begin{tabular}{|l|l|l|l|l|l|}
\hline & \multicolumn{2}{|l|}{ Excessive } & \multicolumn{2}{l|}{ Nonexcessive } & \multirow{2}{*}{$p$-Value } \\
\cline { 2 - 5 } & Mean & \pm SD & Mean & \pm SD & \\
\hline $\begin{array}{l}\text { FFP } \\
\text { transfused }\end{array}$ & 4.55 & \pm 0.93 & 1.90 & \pm 0.44 & $<0.001$ \\
\hline $\begin{array}{l}\text { Platelet } \\
\text { transfused }\end{array}$ & 4.73 & \pm 1.01 & 2.05 & \pm 0.84 & $<0.001$ \\
\hline
\end{tabular}

Abbreviations: FFP, fresh frozen plasma; SD, standard deviation.

\section{Blood and Blood Products Transfused}

In excessive bleeding group post-CPB, mean unit PRBCs transfused was significantly higher $(3.91 \pm 0.94)$ than nonexcessive group ( $1.61 \pm 0.59$; - Table 7$)$.

In excessive bleeding group, mean unit of FFP transfused was $4.55 \pm 0.93$ and in nonexcessive group, the mean unit of platelet transfused was $4.73 \pm 1.01$. Both platelet and FFP transfused were significantly higher in excessive group (-Table 8).

\section{Discussion}

Antiplatelet therapy (APT) is the mainstay of treatment in patients with coronary artery disease. APT causes acquired platelet dysfunction and this group of patients are at high risk for excessive microvascular bleeding and reexploration after CABG. Postoperative bleeding remains one of the major complications of cardiac surgery, and the pivotal role of platelet function must be taken into consideration. ${ }^{23}$ Effect of CPB itself and long CPB causes deranged coagulation and postbypass nonsurgical bleeding. Haensig et al concluded that in patients with long CPB times, ROTEM-guided treatment may result in less bleeding, a marked reduction in costs, and long-term mortality. ${ }^{23}$

Despite this evidence base and the publication of numerous practice guidelines, ${ }^{25}$ much confusion remains about the optimal management of perioperative bleeding in cardiac surgery patients. In contrast with other studies, ${ }^{26}$ we focused on changes in platelet function and identifying the optimum time point for platelet function testing to predict bleeding and transfusion in this setting using ROTEM platelet.

We found significant difference in platelet function were present at T1 and T2 (TRAPTEM, ARATEM, and ADPTEM) in both excessive and nonexcessive bleeding groups. The most consistent results with significant differences in platelet function values between patients with and without excessive bleeding were found at T2 (5-10 minutes after protamine administration) in AUC (TRAPTEM, ARATEM, and ADPTEM). This is consistent with other studies demonstrating the inhibitory effect of CPB on platelet function assay. Velik-Salchner et al found that in patients without antiplatelet drugs, both multiplate and light transmission aggregometry (LTA) methods showed that CPB was associated with significantly decreased platelet aggregation after activation by commonly used agonists. This was also observed in patients taking aspirin or dual antiplatelet therapy for ADP-induced assays. ${ }^{27}$

In our study results, we found no significant difference in preoperative platelet count, nor was the incidence of preoperative intake of antiplatelet drugs, such as aspirin and clopidogrel, different between patients with and without excessive bleeding. In contrast, the presence of excessive bleeding could be discriminated by platelet function testing at $\mathrm{T} 2$. Haas et al concluded that standard laboratory tests were neither designed to accurately reflect compromised thrombin generation nor to guide coagulation therapy and low predictive value of standard laboratory tests to predict postoperative bleeding. ${ }^{28}$ We could not establish the history of discontinuation of antiplatelet therapy as a predictor of postoperative blood loss. We demonstrated that platelet function analysis is superior to history of discontinuation of antiplatelet therapy for predicting bleeding in cardiac surgery. Rahe-Meyer et al also suggested that arachidonic acid-induced aggregation in whole blood may be a better predictor of platelet-related coagulopathy and platelet transfusion than the assessment of aspirin intake by patient self-reporting. ${ }^{29}$

For predicting the bleeding of ROC curve was evaluated for each parameter of all three indices of ROTEM platelet at T2 point. For MS area under the ROC curve, only ADPTEM was found to be significant. For this, a threshold value of $\leq 3.5$ to predict excessive bleeding yields sensitivity of $63.64 \%$, specificity of $63.41 \%$, PPV of $31.32 \%$, NPV of $86.67 \%$, and accuracy of $63.46 \%$. Both sensitivity and specificity were low with NPV of $86.67 \%$. For AUC, for TRAPTEM, a threshold value of $\leq 50$ to 
predict excessive bleeding yielded sensitivity of $90.91 \%$, specificity of $68.29 \%$, PPV of $43.48 \%$, NPV of $96.55 \%$, and accuracy of $73.08 \%$. For ARATEM, a threshold value of $\leq 31.5$ to predict excessive bleeding yielded sensitivity of $81.82 \%$, specificity of $65.85 \%$, PPV of $39.13 \%$, NPV of $93.10 \%$, and accuracy of $69.23 \%$. For ADPTEM, a threshold value of $\leq 32$ to predict excessive bleeding yielded sensitivity of $72.73 \%$, specificity of $87.80 \%$, PPV of $61.54 \%$, NPV of $92.31 \%$, and accuracy of $84.62 \%$.

Cut-off values, as determined by ROC analyses, had a consistently weak PPV for all tests at T2 time point, whereas NPVs were higher and generally had an increasing tendency toward measurements performed at $\mathrm{T} 2$. Ranucci et al ${ }^{5}$ evaluated prediction bleeding using whole blood impedance aggregometry, and reported a low PPV coupled with a high NPV. This was superior in estimating who was likely to not bleed rather than who was likely to bleed. They pointed out that the high NPV of whole blood impedance aggregometry helps to exclude platelet dysfunction as the reason for bleeding after cardiac surgery in case of normal results in the activated by adenosine diphosphate (ADP) activated assay (negative predictive value of $92 \%$ ).

Petricevic et al assessed platelet function by two whole blood impedance aggregometers (ROTEM platelet and Multiplate, using three different activators (arachidonic acid, adenosine diphosphate, and thrombin receptor-activating peptide-6), at three perioperative time points (before anesthesia, after aortic declamping, and 5-10 minutes after protamine administration). ${ }^{30}$ Multiplate ADP test AUC cut-off value was $\leq 27 \mathrm{U}$ to delineate excessive bleeding. For the ROTEM platelet assay ADPTEM, the corresponding AUC cutoff value was $\leq 36 \mathrm{Ohm}$.min. For TRAP test (multiplate) and TRAPTEM (ROTEM platelet), the AUC cut-off value for excessive bleeding was $\leq 77 \mathrm{U}$ and $\leq 46$ minutes, respectively.

Bleeding during and after cardiac surgery usually is multifactorial and platelet function analysis cannot rule out surgical bleeding, as well as coagulopathic bleeding due to hyperfibrinolysis, low fibrinogen, or impaired thrombin. There are many studies demonstrating the predictive value of point-of-care platelet function testing using whole blood impedance aggregometry for postoperative blood loss and transfusion requirements in cardiac surgery. ${ }^{31,32}$ In our study, we assessed prediction of bleeding using ROTEM platelet aggregometry at two different points. At T1, we assessed difference in platelet function due to preoperative factors, like antiplatelet therapy, and at $\mathrm{T} 2$, we evaluated the effect of CPB on platelet function and analyzed their predictive values for postoperative blood loss and gave blood according to an algorithm as depicted in - Fig. $\mathbf{1}$.

We found that platelet function analysis using multiple (Activated by arachidonic acid (ARA), ADP, and Activated by thrombin receptor-activating peptide-6 (TRAP)) activators after $\mathrm{CPB}$ and protamine administration is able to predict postoperative blood loss with high NPV and low NPV. It helps to exclude platelet dysfunction as the reason for bleeding after cardiac surgery. Point-of-care platelet function analysis, particularly in combination with viscoelastic testing, such asthromboelastometry (ROTEM), can reduce perioperative bleeding and transfusion requirements, as well as improve patient outcomes in cardiac surgery. Earlier too, using algorithm and Point of care (POC) testing, the authors have controlled bleeding using the right blood component therapy but in CABG patients, the postoperative transfusion in the excessive bleeding group helped in optimizing patient control. Platelet function test (PFT)-based Point of care (POC) used in an algorithmic manner is where on-pump CABG bleeding control lies today.

\section{Limitations of Study}

In cardiac surgery, there is no agreement on the definition of excessive bleeding. Chest tube drainage does not reflect intraoperative blood loss and transfusion requirements and consists of a mixture of fluids, including actual blood loss, serous drainage, and fluid left in the pleural cavity. It may, therefore, overestimate postoperative blood loss. Our sample size is small because of poor availability of regent and affordability of this costly test. We did not have any provision to compare our test results with established testing platforms like mutilate. Furthermore, the pharmacokinetic analysis of drug levels in blood was not performed in the study.

There are many factors that can influence blood loss after cardiac surgery, we cannot expect strong predictions from a bed-side test assessing only one part of hemostasis, that is, platelet aggregation. Although, there is consensus regarding the dominant role of platelets in hemostasis after cardiac surgery, we believe that adequate interaction of all coagulation components is crucial to achieve adequate hemostasis. For this reason, concomitant use of the platelet aggregometry and thromboelastometry, both pre- and intraoperatively, could provide a complete and more reliable picture of hemostatic disturbances. This would also provide the role of fibrinogen and its interaction with platelets.

In our study, the daily dose of antiplatelet medicine received were not documented. In our study patients undergone CABG had different anesthetic and perfusion teams. Surgery was performed in three units. But all patients had same anesthesia protocol and same standard surgical procedure. In our study, chest drain output was not adjusted to body weight. But in final analysis, we compared the chest drain output with body weight and body mass index.

\section{Conclusion}

Platelet function analysis using multiple (ARA, ADP, and TRAP) activator after protamine administration is able to predict postoperative blood loss with high NPV and low PPV. Therefore, it helps to exclude platelet dysfunction as the reason for bleeding after cardiac surgery. Point-of-care platelet function analysis, particularly in combination with viscoelastic testing such as thromboelastometry (ROTEM), can reduce perioperative bleeding and transfusion requirements, as well as improve patient outcomes in cardiac surgery. Incorporation of platelet function test in transfusion algorithm may further improve patient outcome post cardiac surgery. 


\section{Conflict of Interest}

None declared.

\section{References}

1 Karkouti K, Wijeysundera DN, Yau TM, et al. The independent association of massive blood loss with mortality in cardiac surgery. Transfusion 2004;44(10):1453-1462

2 Christensen MC, Krapf S, Kempel A, von Heymann C. Costs of excessive postoperative hemorrhage in cardiac surgery. J Thorac Cardiovasc Surg 2009;138(03):687-693

3 Ferraris VA, Hochstetler M, Martin JT, Mahan A, Saha SP. Blood transfusion and adverse surgical outcomes: The good and the bad. Surgery 2015;158(03):608-617

4 Paparella D, Brister SJ, Buchanan MR. Coagulation disorders of cardiopulmonary bypass: a review. Intensive Care Med 2004;30 (10):1873-1881

5 Ranucci M, Baryshnikova E, Castelvecchio S, Pelissero GSurgical and Clinical Outcome Research (SCORE) Group. Major bleeding, transfusions, and anemia: the deadly triad of cardiac surgery. Ann Thorac Surg 2013;96(02):478-485

6 Sellman M, Intonti MA, Ivert T. Reoperations for bleeding after coronary artery bypass procedures during 25 years. Eur J Cardiothorac Surg 1997;11(03):521-527

7 Dacey LJ, Munoz JJ, Baribeau YR, et al; Northern New England Cardiovascular Disease Study Group. Reexploration for hemorrhage following coronary artery bypass grafting: incidence and risk factors. Arch Surg 1998;133(04):442-447

8 Frankel TL, Stamou SC, Lowery RC, et al. Risk factors for hemorrhagerelated reexploration and blood transfusion after conventional versus coronary revascularization without cardiopulmonary bypass. Eur J Cardiothorac Surg 2005;27(03):494-500

9 Rinder CS, Bohnert J, Rinder HM, Mitchell J, Ault K, Hillman R. Platelet activation and aggregation during cardiopulmonary bypass. Anesthesiology 1991;75(03):388-393

10 Holloway DS, Summaria L, Sandesara J, Vagher JP, Alexander JC, Caprini JA. Decreased platelet number and function and increased fibrinolysis contribute to postoperative bleeding in cardiopulmonary bypass patients. Thromb Haemost 1988;59(01):62-67

11 Kozek-Langenecker SA, Afshari A, Albaladejo P, et al. Management of severe perioperative bleeding: guidelines from the European Society of Anaesthesiology. Eur J Anaesthesiol 2013;30(06):270-382

12 Windecker S, Kolh P, Alfonso F, et al; Authors/Task Force members. 2014 ESC/EACTS Guidelines on myocardial revascularization: The Task Force on Myocardial Revascularization of the European Society of Cardiology (ESC) and the European Association for CardioThoracic Surgery (EACTS)Developed with the special contribution of the European Association of Percutaneous Cardiovascular Interventions (EAPCI). Eur Heart J 2014;35(37):2541-2619

13 Anderson JL, Adams CD, Antman EM, et al. 2012 ACCF/AHA focused update incorporated into the ACCF/AHA 2007 guidelines for the management of patients with unstable angina/non-STelevation myocardial infarction: a report of the American College of Cardiology Foundation/American Heart Association Task Force on Practice Guidelines. J Am Coll Cardiol 2013;61(23):e179-e347

14 Di Dedda U, Ranucci M, Baryshnikova E, Castelvecchio SSurgical and Clinical Outcome Research Group. Thienopyridines resistance and recovery of platelet function after discontinuation of thienopyridines in cardiac surgery patients. Eur J Cardiothorac Surg 2014;45(01):165-170

15 Reece MJ, Klein AA, Salviz EA, et al. Near-patient platelet function testing in patients undergoing coronary artery surgery: a pilot study. Anaesthesia 2011;66(02):97-103

16 Murphy GJ, Reeves BC, Rogers CA, Rizvi SI, Culliford L, Angelini GD. Increased mortality, postoperative morbidity, and cost after red blood cell transfusion in patients having cardiac surgery. Circulation 2007;116(22):2544-2552
17 Weber CF, Görlinger K, Meininger D, et al. Point-of-care testing: a prospective, randomized clinical trial of efficacy in coagulopathic cardiac surgery patients. Anesthesiology 2012;117(03):531-547

18 Ranucci M, Baryshnikova E, Soro G, Ballotta A, De Benedetti D, Conti DSurgical and Clinical Outcome Research (SCORE) Group. Multiple electrode whole-blood aggregometry and bleeding in cardiac surgery patients receiving thienopyridines. Ann Thorac Surg 2011;91(01):123-129

19 Cannon CP, Mehta SR, Aranki SF. Balancing the benefit and risk of oral antiplatelet agents in coronary artery bypass surgery. Ann Thorac Surg 2005;80(02):768-779

20 Sharan S, Gandhi A, Kapoor PM. Utility of Platelet Function Tests: A Recent Review Round Up. J Cardiac Crit Care TSS 2019;03(01): 24-27

21 Bhardwaj V, Kapoor PM. Platelet aggregometry interpretation using ROTEM - PART - II. Ann Card Anaesth 2016;19(04):584-586

22 Levy JH, Tanaka KA, Steiner ME. Evaluation and management of bleeding during cardiac surgery. Curr Hematol Rep 2005;4(05): 368-372

23 Haensig M, Kempfert J, Kempfert PM, Girdauskas E, Borger MA, Lehmann S. Thrombelastometry guided blood-component therapy after cardiac surgery: a randomized study. BMC Anesthesiol 2019;19(01):201

24 Boer C, Meesters MI, Milojevic M, et al; Task Force on Patient Blood Management for Adult Cardiac Surgery of the European Association for Cardio-Thoracic Surgery (EACTS) and the European Association of Cardiothoracic Anaesthesiology (EACTA) 2017 EACTS/EACTA guidelines on patient blood management for adult cardiac surgery. J Cardiothorac Vasc Anesth 2018;32 (01):88-120

25 Ferraris VA, Ferraris SP, Saha SP, et al. Society of Thoracic Surgeons Blood Conservation Guideline Task Force; Society of Cardiovascular Anesthesiologists Special Task Force on Blood Transfusion. Perioperative blood transfusionand blood conservation in cardiac surgery: the Society of Thoracic Surgeons and the Society of CardiovascularAnesthesiologists clinical practice guideline. Ann Thorac Surg 2007;83:S27-S86

26 Velik-Salchner C, Maier S, Innerhofer P, et al. An assessment of cardiopulmonary bypass-induced changes in platelet function using whole blood and classical light transmission aggregometry: the results of a pilot study. Anesth Analg 2009;108(06): $1747-1754$

27 Haas T, Fries D, Tanaka KA, Asmis L, Curry NS, Schöchl H. Usefulness of standard plasma coagulation tests in the management of perioperative coagulopathic bleeding: is there any evidence? Br J Anaesth 2015;114(02):217-224

28 Rahe-Meyer N, Winterhalter M, Hartmann J, et al. An evaluation of cyclooxygenase-1 inhibition before coronary artery surgery: aggregometry versus patient self-reporting. Anesth Analg 2008; 107(06):1791-1797

29 Petricevic M, Kopjar T, Biocina B, et al. The predictive value of platelet function point-of-care tests for postoperative blood loss and transfusion in routine cardiac surgery: a systematic review. Thorac Cardiovasc Surg 2015;63(01):2-20

30 Petricevic M, Konosic S, Biocina B, et al. Bleeding risk assessment in patients undergoing elective cardiac surgery using ROTEM platelet and Multiplate impedance aggregometry. Anaesthesia 2016;71(06):636-647

31 Corredor C, Wasowicz M, Karkouti K, Sharma V. The role of pointof-care platelet function testing in predicting postoperative bleeding following cardiac surgery: a systematic review and meta-analysis. Anaesthesia 2015;70(06):715-731

32 Karanjkar A, Kapoor PM, Sharan S, et al. A prospective randomized clinical trial of efficacy of algorithm-based point of care guided hemostatic therapy in cyanotic congenital heart disease surgical patients. J Card Crit Care 2020;3:8-16 